\title{
Robinijeva grizlica, Nematus tibialis, nova tujerodna vrsta $v$ Sloveniji
}

\author{
Maarten DE GROOT ${ }^{1 *}$, Andreja KAVČIČ ${ }^{1}$
}

\section{UVOD}

Navadna robinija (Robina pseudoacacia L.) je drevesna vrsta, ki izvira iz Združenih držav Amerike. Vrsta je bila v začetku 17. stoletja s pomočjo človeka vnesena v Evropo, kjer velja za tujerodno vrsto (Sitzia in sod., 2016). Je vsestransko uporabna, zato so jo v Sloveniji v preteklosti sadili kot gospodarsko pomembno drevo in za utrjevanje brežin ter jo do danes večinoma tudi vzeli za svojo. Cenjena je zaradi lesa, priljubljena je tudi kot okrasno drevo. Še posebej pa jo imajo radi čebelarji, saj njeni cvetovi obilno medijo in so pomembna čebelja paša, ki daje kakovosten in visoko cenjen akacijev med. Navadna robinija je na območju Slovenije splošno razširjena (Rudolf, 2004). Vrsta se uspešno samostojno razmnožuje, se močno in hitro razrašča ter zlahka zasede nova območja. Pri tem siromaši tla nekaterih mineralov in izpodriva domorodne vrste dreves in grmov, vendar pa po drugi strani tla bogati z dušikom.

Na navadni robiniji je bilo opisanih več vrst škodljivcev in bolezni, vendar o večjem vplivu posameznih škodljivih dejavnikov na drevo ni poročil (Kulfan, 2012). V zadnjih desetletjih se pojavlja vedno več novih bolezni in škodljivcev lesnatih in drugih rastlin, ki na območja, kjer prej niso bili prisotni, prihajajo s pomočjo človeka. Velik delež teh, ti. tujerodnih vrst, v Evropo pride iz Združenih držav Amerike (Zúbrik in sod., 2013).

Eden od tujerodnih škodljivcev lesnatih rastlin, ki izvirajo iz Združenih držav Amerike, je robinijeva grizlica, Nematus tibialis Newman, 1837. Vrsta je v Evropo domnevno prišla $\mathrm{z}$ gostiteljskimi rastlinami. V literaturi je bila ta vrsta v Evropi prvič omenjena leta 1837 v Veliki Britaniji (Newman, 1837). Do danes se je razširila po številnih evropskih državah. Čeprav je vrsta že dlje časa prisotna tudi v vseh naših sosednjih državah, v Italiji, v Avstriji, na Madžarskem in na Hrvaškem (Schedl, 2010; Kofler in Schedl, 2014; DAISIE, 2017), je bila v Sloveniji prvič opažena šele pred kratkim.

Robinijeva grizlica je bila v Sloveniji prvič najdena 25. maja 2017, in sicer v osrednjem delu Slovenije, v Ljubljani v gozdu na Rožniku, ki je del krajinskega parka Tivoli, Rožnik, Šišenski hrib (GKX: 101049 m, GKY: 460038 m). Najdena je bila ena ličinka (pagosenica), ki se je prehranjevala na listu mlade rastline navadne robinije (slika 1). Na listu je bila jasno izražena značilna luknjasta izjedina $v$ sredini lamine enega od lističev. Značilne poškodbe na listih navadne robinije zaradi prehranjevanja ličink robinijeve grizlice so bile kasneje opažene tudi v bližini krajev Nazarje (GKX: 129755 m, GKY: 491566 m), Srednja Bistrica (GKX: 155835 m, GKY: 598090 m) in Kostanjevica na Krki (GKX: 76777 m, GKY: 533528 m).

\section{OPIS}

Robinijeva grizlica, Nematus tibialis, je rastlinska osa iz družine listaric (Hymenoptera, Tenthredinidae), ki je naravno razširjena v Severni Ameriki (Hargrove, 1986). Robinijeva grizlica se pojavlja na različnih vrstah robinije (Robinia spp.) (Liston, 2011; Alford, 2012).

Odrasle grizlice v dolžino merijo 6 do $7 \mathrm{~mm}$. Imajo rumeno telo ter črne oči in antene. Na glavi in na hrbtni strani oprsja in zadka imajo bleščeče črne proge. Proge na zadku so prečne, po ena na vsakem zadkovem členu. Noge imajo pretežno rumene, s temnejšimi stopalci na prvem in drugem paru, ter črnimi golenmi in stopalci na tretjem paru (Alford, 2012). Krila so prosojna z izrazito ožiljenostjo. Žile na krilih so črne (Newman, 1837).

Pagosenica robinijeve grizlice v dolžino zraste do 12 $\mathrm{mm}$. Ima bleščeče svetlo zeleno telo in svetlo rjavo glavo (Alford, 2012). Ima tri pare oprsnih nog in šest parov nepravih nog (panožic) na zadku. Pagosenice se prehranjujejo z listi robinije. List začnejo objedati v sredini listne ploskve, pri čemer nastajajo značilne luknjaste izjedine (Zúbrik in sod., 2013) (slika 1). Izjedina se sčasoma povečuje in pagosenice pojejo list v celoti, zaradi česar lahko ob večji namnožitvi pride do izgube listov oz. defoliacije.

\section{BIOLOGIJA}

Robinijeva grizlica je oligofagna rastlinojeda žuželka. Pojavlja se na različnih vrstah dreves iz rodu Robinia, kjer se ličinke prehranjujejo z listnim tkivom. Robinijeva grizlica je bila najdena na navadni robiniji (Robinia pseudoacacia L.) (Hargrove 1986) in na lepljivi robiniji (Robinia viscosa Vent.) (Liston, 2011). $\mathrm{V}$ sestojih robinije je robinijeva grizlica bolj pogosta $\mathrm{V}$ notranjosti sestojev kot na robnih delih (Bakay in Kollar, 2010).

Robinijeva grizlica je aktivna od maja do septembra (Alford, 2012). V Srednji Evropi lahko v eni sezoni razvije eno do dve generaciji (Zubrik in sod., 2013). Prva generacija se pojavi v času od maja do junija (Schwenke, 1982; Alford, 2012), druga pa se razvije pozno poleti (Alford, 2012). V letih z ugodnimi razmerami se lahko jeseni pojavi tudi tretja generacija (Alford, 2012).

Samica robinijeve grizlice odlaga jajčeca brez predhodne oploditve (partenogeneza). Jajčeca odloži na liste mladih poganjkov robinije. Iz jajčec se po nekaj dneh izležejo ličinke, ki se prehranjujejo $\mathrm{z}$ listnim tkivom. Raziskave so pokazale, da je prehranjevanje najbolj intenzivno pri temperaturi $30^{\circ} \mathrm{C}$ (Lemoine in sod., 2014). Po 2 do 3 tednih se pagosenica spusti v tla, kjer se zabubi $\mathrm{v}$ trpežnem temno rjavem kokonu. Odrasli osebki se pojavijo po nekaj tednih (Alford, 2012). 
Kot naravni sovražnik robinijeve grizlice je bila opisana parazitoidna osica Trichogramma aurosum Sugonjaev \& Sorokina, 1976 (Hymenoptera, Trichogrammatidae), ki je parazitoid jajčec. T. aursom je prisotna tudi v Evropi (Samara in sod., 2011).

\section{VPLIV}

Vpliv robinijeve grizlice zaradi luknjastega objedanja robinijevih listov, ki ga povzročajo pagosenice, je po trenutno dostopnih podatkih zanemarljiv. Na listih navadne robinije poleg robinijeve grizlice najdemo še tri tujerodne vrste žuželk, ki pa so v Sloveniji znane že dlje časa, in sicer metulja iz družine zavitkarjev listni zavrtač robinije Macrosaccus robiniella (Clemens, 1859) in robinijev listni zavrtač Parectopa robiniella Clemens, 1863 (Lepidoptera, Gracillariidae) ter robinijeva listna šiškarica Obolodiplosis robiniae (Haldeman, 1847) (Diptera, Cecidomyiidae), ki prav tako kot robinijeva grizlica nimajo pomembnejšega vpliva na drevo. Ne glede na to pa lahko v primeru večjih namnožitev robinijeva grizlica in druge omenjene vrste negativno vplivajo na estetski izgled dreves, ki so gojena v okrasne namene, in na tržno vrednost sadik, gojenih za prodajo v drevesnicah (Alford, 2012). Iz Rusije poročajo o 4-5 \% napadenosti posameznih dreves z robinijevo grizlico, na posameznem lističu pa je bilo najdenih do 10 pagosenic te grizlice (Sinchuk in sod., 2015).

\section{ZAKLJUČEK}

Robinijeva grizlica je nova tujerodna vrsta rastlinske ose v Sloveniji. Pojavlja se na različnih vrstah robinije (Robinia spp.), kjer njene pagosenice luknjasto obžirajo liste. Njen vpliv na robinijo je zanemarljiv. Glede na najdbe na lokacijah $\mathrm{v}$ različnih delih Slovenije sklepamo, da je robinijeva grizlica v Sloveniji že precej razširjena, vendar je njena številčnost zaenkrat majhna.

\section{Viri}

Alford D.V. 2012. Pests of Ornamental Trees, Shrubs and Flowers: A Color Handbook. Elsevier Academic Press: 480 str. https://books.google.si/books?id=c9PwiScwmPIC
Bakay L., Kollar J. 2010. Insect pests on the black locust (Robinia pseudoacacia L.) in the locality Čebovce. Acta horticulturae et regiotecturae, special issue: 55-57.

DAISIE. 2017. Species factsheet Nematus tibialis. http://www.europealiens.org/speciesFactsheet.do?speciesId=50671\# (4.7.2017)

Hargrove W.W. 1986. An annotated species list of insect herbivores commonly associated with black locust, Robinia pseudoacacia, in the Southern Appalachians. Entomological News, 97, 1: 36-40.

Kofler A., Schedl W. 2014. Zum Vorkommen von Pflanzenwespen in Osttirol 5.Teil (Hymenoptera: Symphyta: Tenthredinidae: Nematinae). Ber. nat.-med. Verein Innsbruck, 99: 91-102.

Kulfan M. 2012. Lepidoptera on the introduced Robinia pseudoacacia in Slovakia, Central Europe. Check List, 8, 4: 709-711.

Lemoine N.P., Burkepile D.E., Parker J.D. 2014. Variable effects of temperature on insect herbivory. PeerJ, 2: e376.

Liston A.D. 2011. New hostplant records for European sawflies (Hymenoptera, Tenthredinidae). Entomologist's monthly magazine, 146: $189-193$.

Newman E. 1837. Notes on Tenthredinina. The Entomological Magazine, 4: 258-263.

Rudolf S. 2004. Robinija (Robinia pseudoacacia 1.) v severovzhodni Sloveniji. Diplomsko delo - visokošolski strokovni študij. Ljubljana, Univerza v Ljubljani, Oddelek za gozdarstvo in obnovljive gozdne vire: 82 str.

Samara R., Monje J.C., Zebitz C.P.W., Qubbaj T. 2011. Comparative biology and life tables of Trichogramma aurosum on Cydia pomonella at constant temperatures. Phytoparasitica, 39, 2: 109-119.

Schedl W. 2010. Die Pflanzenwespen im Botanischen Garten Innsbruck (Tirol, Österreich) Artengarnitur, Blütenbesuch und Phänologie (Insecta: Hymenoptera: Symphyta). Ber. nat.-med. Verein Innsbruck, 96: 93-104.

Schwenke W. 1982. Die forstschadlinge europas: 4. Hautflugler un zweiflugler. Hamburg, Verlag Paul Parey: 392 str.

Sinchuk A.V., Roginsky A.S., Buga S.V. 2015. The first registration of locust sawfly (Nematus tibialis Newman, 1837) in Bryansk region. Proceedings of the Belarusian State University, 10, 1:374-376.

Sitzia T., Cierjacks A., de Rigo D., Caudullo G. 2016. Robinia pseudoacacia in Europe: distribution, habitat, usage and threats. V: European Atlas of Forest Tree Species. San-Miguel-Ayanz J., de Rigo D., Caudullo G., Houston Durrant T., Mauri A. (ur.). Luxembourg, Publ. Off. EU: e014e79.

Zúbrik M., Kunca A., Csóka G. 2013. Insects and Diseases Damaging Trees and Shrubs of Europe: A Colour Atlas. NAP Editions: 535 str. https://books.google.si/books?id=kf9inQEACAAJ

${ }^{1}$ Gozdarski inštitut Slovenije, Večna pot 2, 1000 Ljubljana *maarten.degroot@gozdis.si

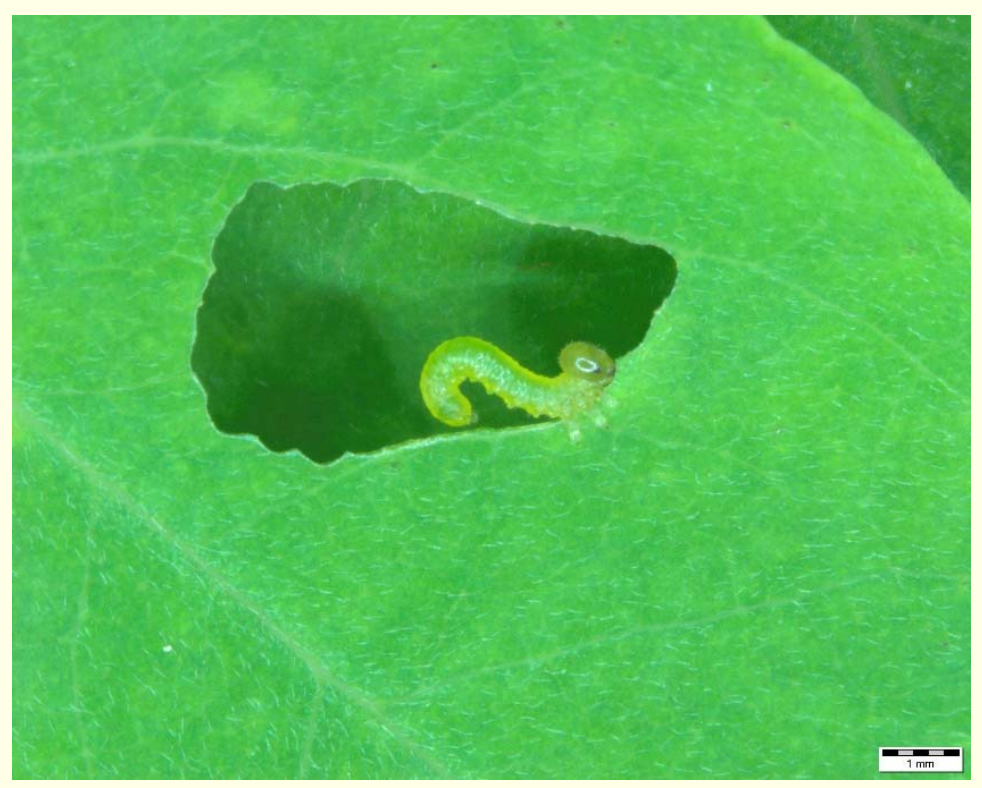

Slika 1: Pagosenica robinijeve grizlice in značilna poškodba lista (foto: Maarten de Groot) 